\title{
Letter to the Editor regarding "Simultaneous determination of residues in pollen and high-fructose corn syrup from eight neonicotinoid insecticides by liquid chromatography-tandem mass spectrometry"
}

\author{
S. D. Whipple
}

Received: 14 November 2014 / Accepted: 28 November 2014/Published online: 27 December 2014

(C) Springer-Verlag Berlin Heidelberg 2014

Dear Sirs,

This letter serves as a formal rebuttal to the manuscript entitled "Simultaneous determination of residues in pollen and high-fructose corn syrup from eight neonicotinoid insecticides by liquid chromatography-tandem mass spectrometry" by Mei Chen, Erin M. Collins, Lin Tao, and Chensheng Lu published November 2013 in the journal Analytical and Bioanalytical Chemistry 405(28): 9251-64 (doi:10.1007/s00216-013-7338-7) [1]. The claim that the product flonicamid is a neonicotinoid, and therefore toxic to honeybees and other pollinators, is completely unsubstantiated and incorrect.

According to the Insecticide Resistance Action Committee (IRAC) [2], neonicotinoids are in IRAC Group 4A with the mode of action being nicotinic acetylcholine receptor (nAChR) agonists, requiring strong evidence that action at one or more of this class of protein is responsible for insecticidal effects. This includes the following IRAC subgroups:

- IRAC Group 4A: Neonicotinoids including acetamiprid, clothianidin, dinotefuran, imidacloprid, nitenpyram, thiacloprid, thiamethoxam

- IRAC Group 4B: nicotine

- IRAC Group 4C: sulfoxaflor

Flonicamid is a selective homopteran feeding blocker in IRAC Group 9C, and is the only compound in this chemical subgroup. Flonicamid has no effect on the

S. D. Whipple $(\bowtie)$

Field Development Representative, ISK Biosciences Corporation, 211 S. Platte Clay Way, Suite B, Kearney, MO 64060, USA

e-mail: whipples@iskbc.com
nAChR and according to both the IRAC and the EPA, flonicamid is not a neonicotinoid by classification or mode of action $[2,3]$.

Furthermore, the EPA-EFED (Environmental Protection Agency - Environmental Fate and Effects Division) has concluded that flonicamid (Beleaf 50SG/Carbine 50WG) has low risk to bees $\left(\mathrm{LD}_{50}>50 \mu \mathrm{g}\right.$ a.i./bee) which is confirmed in numerous publications and is widely recognized [3-6]. Therefore, the claim that flonicamid is a neonicotinoid and toxic to pollinators is incorrect.

\section{References}

1. Chen M, Collins EM, Tao L, Lu C (2013) Simultaneous determination of residues in pollen and high-fructose corn syrup from eight neonicotinoid insecticides by liquid chromatography-tandem mass spectrometry. Anal Bioanal Chem 405:9251-9264

2. Insecticide Resistance Action Committee (IRAC) 2014 IRAC MoA classification scheme. http://www.irac-online.org/teams/ mode-of-action/

3. Laurentie D, Morita M (2005) La flonicamide: un nouvel aphicide. AFPP- $7^{\mathrm{e}}$ Conférence Internationale sur les ravageurs en agriculture, Montpellier, 26-27 Oct 2005

4. Kurpke CH, Hunt G, Foster RE (2012) Purdue University pollinator protection bulletin E-53: Table 3. Flonicamid (Beleaf 50SG) - relatively nontoxic pesticides. Materials in this group can be used with few precautions and a minimum of injury to bees. http://extension.entm. purdue.edu/publications/E-53.pdf

5. University of California Davis (2013) Integrated pest management website: flonicamid (Carbine 50WG in cotton) is recognized as a selective feeding inhibitor (not a neonicotinoid) as well as low risk to bees. http://www.ipm.ucdavis.edu/PMG/ r114900911.html

6. Ontario Ministry of Agriculture, Food and Rural Affairs (2013) Guide to fruit production 2012-2013. Chap 13: information on pesticides. Publication 360, Ontario Ministry of Agriculture, Food and Rural Affairs, Guelph, Ontario 